\title{
Genetic parameters of dairy cow energy intake and body energy status predicted using mid-infrared spectrometry of milk
}

\author{
S. McParland, ${ }^{1}$ E. Kennedy, E. Lewis, S. G. Moore, B. McCarthy, M. O'Donovan, and D. P. Berry \\ Animal and Grassland Research and Innovation Center, Teagasc, Moorepark, Fermoy, Co. Cork, Ireland
}

\section{ABSTRACT}

Energy balance (EB) and energy intake (EI) are heritable traits of economic importance. Despite this, neither trait is explicitly included in national dairy cow breeding goals due to a lack of routinely available data from which to compute reliable breeding values. Mid-infrared (MIR) spectrometry, which is performed during routine milk recording, is an accurate predictor of both EB and EI. The objective of this study was to estimate genetic parameters of EB and EI predicted using MIR spectrometry. Measured EI and EB were available for 1,102 Irish Holstein-Friesian cows based on actual feed intake and energy sink data. A subset of these data (1,270 test-day records) was used to develop equations to predict EI, EB, and daily change in body condition score $(\triangle \mathrm{BCS})$ and body weight $(\triangle \mathrm{BW})$ using the MIR spectrum with or without milk yield also as a predictor variable. Accuracy of cross-validation of the prediction equations was $0.75,0.73,0.77$, and 0.70 for EI, EB, $\triangle \mathrm{BCS}$, and $\triangle \mathrm{BW}$, respectively. Prediction equations were applied to additional spectral data, yielding up to 94,653 records of MIR-predicted EI, EB, $\triangle \mathrm{BCS}$, and $\triangle \mathrm{BW}$ available for variance component estimation. Variance components were estimated using repeatability animal linear mixed models. Heritabilities of MIR-predicted EI, EB, $\triangle \mathrm{BCS}$, and $\triangle \mathrm{BW}$ were 0.20 , $0.10,0.07$, and 0.06 , respectively; heritability estimates of the respective measured traits were $0.35,0.16,0.07$, and 0.08 , respectively. The genetic correlation between measured and MIR-predicted EI was 0.84 and between measured and MIR-predicted EB was 0.54, indicating that selection based on MIR-predicted EI or EB would improve true EI or EB. Genetic and phenotypic associations between EI and both the milk production and body-change traits were generally in agreement, regardless of whether measured EI or MIR-predicted EI was considered. Higher-yielding animals of higher body weight had greater EI. Predicted EB was negatively genetically correlated with milk yield (genetic correla-

Received September 24, 2014.

Accepted November 4, 2014.

${ }^{1}$ Corresponding author: sinead.mcparland@teagasc.ie tion $=-0.29)$ and positively genetically correlated with both milk fat and protein percent (genetic correlation $=0.17$ and 0.16 , respectively). Least squares means phenotypic EI of 198 animals stratified as low, average, and high estimated breeding values for MIR-predicted EI (animal phenotypes were not included in the genetic evaluation) were $154.3,156.0$, and $163.3 \mathrm{MJ} / \mathrm{d}$, corroborating that selection on MIR-predicted EI will, on average, result in differences in phenotypic true EI.

Key words: energy balance, feed intake, mid-infrared spectrometry, genetic parameters

\section{INTRODUCTION}

It is generally accepted that animal energy balance (EB), especially in early lactation, is both phenotypically (Beam and Butler, 1999) and genetically (Collard et al., 2000) correlated with animal health and fertility. Multi-trait genetic evaluations, including heritable correlated traits, can be used to augment the accuracy of selection for low-heritability traits such as animal health (Berry et al., 2011) and fertility (Berry et al., 2014a). Previously reported heritability estimates for EB (Veerkamp et al., 2000; Berry et al., 2007; Banos and Coffey, 2010), coupled with the known genetic correlations with health and fertility (Collard et al., 2000; Veerkamp et al., 2000), suggest that EB could indeed be a useful trait in a multi-trait genetic evaluation for animal health and fertility. Energy balance also has an economic value in its own right (Wall et al., 2008). Routine access to accurate data on energy intake (EI), or EB, on a large number of animals to undertake genetic evaluations is, however, currently prohibitively expensive. Mid-infrared (MIR) spectroscopy is the technology used during routine milk recording to predict milk fat, protein, and lactose contents of milk and has recently been associated with novel milk quality traits such as individual milk fats and proteins (Soyeurt et al., 2011; De Marchi et al., 2014). McParland et al. (2011, 2012, 2014) reported that both EI and EB can be predicted phenotypically from MIR spectroscopy analysis of raw milk. The advantage of using milk MIR in the prediction of EI and EB is that MIR information is potentially available on all milk samples taken 
from individual cows at routine milk testing. Therefore, EI and EB predictions for individual cows could be obtained at little or no marginal cost above that of routine milk testing. Heretofore, studies that demonstrated the ability of milk MIR to predict cow EI and EB were at the phenotypic level (McParland et al., 2011, 2012, 2014). The objective of this study was (1) to quantify the genetic variation in the MIR-predicted EI and EB phenotypes, and (2) to quantify their genetic association with EI and EB measured using conventional methods. Results from this study will be useful in determining the suitability of MIR-predicted phenotypes in dairy cattle breeding programs as a measure of EI and EB.

\section{MATERIALS AND METHODS}

\section{Data}

Data originated from 9 dairy research herds located throughout Ireland and operated by the Teagasc Animal and Grassland Research and Innovation Center (Moorepark, Fermoy, Co. Cork, Ireland) between the years 2000 and 2013 inclusive. The majority of cows used in this study participated in ongoing grazing studies at the time of data collection and were offered a basal diet of grazed grass (Ganche et al., 2013; McCarthy et al., 2014). Historical data used in this study were previously described by O'Neill et al. (2013). Individual cow DMI was periodically recorded at grass using the $n$-alkane technique and fecal grab samples (Dillon and Stakelum, 1989) up to 8 times across lactation, as previously described by Kennedy et al. (2008). The procedure provides a measure of DMI averaged across $6 \mathrm{~d}$ of sampling. The ME content of the grass was assumed to be $0.0157 \times$ digestible OM of grass (AFRC, 1993) sampled from the paddock immediately before grazing during the feed intake measurement period. Grass metabolizable EI was summed with metabolizable EI from the concentrate fed (up to $6.2 \mathrm{~kg}$ daily with an assumed energy content of $12.5 \mathrm{MJ} / \mathrm{kg}$; O'Mara, 1997) to obtain a measure of total metabolizable EI. A subset of the data used in the present study was obtained from animals housed in a freestall barn where DMI was recorded daily using the Griffith Elder feeding system (Griffith Elder Ltd., Bury St. Edmunds, UK). The typical diet of the housed animals was a TMR diet of grass silage, maize silage, soybean meal, molasses, and dairy concentrate (O'Neill et al., 2011; Moore et al., 2014). Metabolizable EI was computed for all animals with intake records according to the formulas of Coffey et al. (2001).

Cows were milked twice daily at 0700 (AM) and 1500 $\mathrm{h}(\mathbf{P M})$, and individual cow milk yield was recorded at each milking. Individual cow milk samples were taken at consecutive PM and AM milkings once weekly. All milk samples were analyzed using an MIR spectrometer (Milkoscan FT6000; Foss, Hillerød, Denmark), and the resulting spectra were stored for samples obtained between the years 2008 and 2013 inclusive. The Foss MIR spectrum contains 1,060 data points that represent the absorption of infrared light through the milk sample at wavelengths in the 900 to $5,000 \mathrm{~cm}^{-1}$ region. Spectral data were transformed from transmittance to linear absorbance values using a $\log _{10}$ transformation of the reciprocal of the wavelength value. Only spectral data from between 5 and 305 DIM (inclusive) were retained for analysis. In total, 118,769 milk spectral data from 5,197 lactations on 2,485 cows from 2008 to 2013 were available.

Body weight of all cows was measured weekly following the AM milking using weighing scales. Body condition score was assessed by trained scorers every 2 to 3 wk on a scale of 1 to 5 in increments of 0.25 units; a score of 1 represented emaciated animals and a score of 5 represented extremely fat animals (Edmonson et al., 1989). Cubic splines with 6 knot points at 20, 70, 120, 170, 220, and 270 DIM were fitted through individual test-day records of BW and BCS with a covariance structure fitted among knot points. Body weight and BCS at each DIM were interpolated from the fitted splines. Forward differencing was used to estimate daily BCS change $(\boldsymbol{B} \mathbf{B C S})$ and daily BW change $(\boldsymbol{\Delta B W})$ for each DIM. To prevent error accumulation through extrapolation of data beyond the recording period, records of $\triangle \mathrm{BW}$ and $\triangle \mathrm{BCS}$ were retained only for weeks that had an actual BW or BCS recorded, respectively. Energy balance was calculated as the difference between EI and energy expended through milk production and maintenance, as outlined in Banos and Coffey (2010) for all cows with EI recorded between 2000 and 2013 inclusive. Traits calculated using recorded phenotypic data are further referred to as measured EI, EB, $\triangle \mathrm{BCS}$, and $\triangle \mathrm{BW}$.

\section{Prediction Equations}

All records from 2008 to 2013 with an MIR spectrum and a corresponding $\triangle \mathrm{BCS}(\mathrm{n}=28,336)$ or $\triangle \mathrm{BW}$ (n $=51,511$ ) were retained for development of prediction equations. A subset of 1,270 records with spectral information obtained within 1 wk of the date of recording of the component traits of $\mathrm{EB}$ was retained to develop equations to predict $\mathrm{EB}$ and EI. Equations to predict $\triangle \mathrm{BW}$ and $\triangle \mathrm{BCS}$ were developed using (1) all $\triangle \mathrm{BW}$ and $\triangle \mathrm{BCS}$ data recorded between 2008 and 2013, and (2) the reduced data set used for EB and EI prediction equation development. Equations were developed according to the methodology outlined in detail by McParland et al. (2011, 2012, 2014), which exploited 
information on regions of the MIR spectrum with and without milk yield as predictor variables. Equations tested included (1) using PM spectra with and without milk yield as a predictor, and (2) using AM and PM spectra jointly, with and without milk yield as a predictor. Accuracy of all equations was quantified using split-sample cross-validation where every 20th sample was removed from the calibration data set and predicted from the remaining samples. This was iterated until all samples had been predicted once. Equations were subsequently applied to remaining spectral data $(\mathrm{n}=117,499)$ to estimate variance components of MIR-predicted EI, EB, $\triangle \mathrm{BCS}$, and $\triangle \mathrm{BW}$.

\section{Variance Component Analysis}

The expected biological range of EI, EB, $\triangle \mathrm{BCS}$, and $\triangle \mathrm{BW}$ was determined from the respective measured traits; corresponding predicted variables outside of these ranges were considered outliers and subsequently removed. Breed of animal $(\mathrm{n}=5)$ was categorized according to the main breed fraction of the animal, whereby animals with at least $87.5 \%$ of one known breed were classified as purebred ( $\mathrm{n}=3 ; 1=$ Holstein, Friesian, and Holstein-Friesian; 2 = Jersey; $3=$ Norwegian Red), otherwise animals were classified as crossbred $(\mathrm{n}=2 ; 1=$ Jersey crossbred where up to $87.5 \%$ of the known breed was Jersey, 2 = other crossbred). Herd was defined as research farm $(\mathrm{n}=9)$. Season of calving was defined with 6 levels (January, February, March, April, May to August inclusive, and September to December inclusive), reflecting the seasonal system of milk production in Ireland (Berry et al., 2013). Parity numbers greater than 5 were grouped together for analysis.

The final data set comprised 6,391 measured EI and EB records from 1,102 cows; 22,682 measured $\triangle \mathrm{BCS}$; and 44,757 measured $\Delta \mathrm{BW}$ records from 1,809 and 2,022 cows, respectively; and up to 94,653 MIR-predicted EI, $\mathrm{EB}, \triangle \mathrm{BCS}$ and $\triangle \mathrm{BW}$ records from 2,441 cows. Variance components for measured and MIR-predicted EI, $\mathrm{EB}, \triangle \mathrm{BCS}$, and $\triangle \mathrm{BW}$ and (co)variances between traits were estimated using univariate and bivariate repeatability animal linear mixed models in ASReml (Gilmour et al., 2009). Bivariate models including MIR-predicted $\triangle \mathrm{BCS}$ or $\triangle \mathrm{BW}$ involved predictions obtained from the full data set only. All models were adjusted for the fixed effects of herd-test-date, as well as a 3-way interaction between parity, breed, and a fourth-order polynomial of DIM. A random additive genetic effect of animal and a random permanent environmental effect of cow-parity were also fitted in all models. A pedigree file, at least 4 generations deep (where available), was generated for all animals included in the analysis and comprised 9,399 individual animals.

\section{Validation of Estimated Breeding Values}

Breeding values for MIR-predicted EI were estimated for 198 animals with a measured EI in the year 2010; all records of MIR-predicted EI from these 198 animals in all years were excluded from the breeding value estimation to avoid any environmental covariance. Predicted breeding values of MIR-predicted EI were stratified into 3 groups: low, medium, and high, with average MIRpredicted EI of $-1.5,4.4$, and 10.2 MJ, respectively. A mixed model with the fixed effects of herd-test-date, parity, DIM, and measured breeding value stratum was undertaken in PROC MIXED (SAS Institute, 2009) to quantify the least squares means of measured EI for each stratum of MIR-predicted EI breeding values. Cow was included as a repeated effect with a first-order autoregressive covariance structure assumed among records within cow. In a separate analysis, estimated breeding values for MIR-predicted EI stratum were replaced by estimated breeding values for MIR-predicted EI as a continuous variable.

\section{RESULTS}

Data between 7 and 277 DIM were used to develop the MIR prediction equations for EI, EB, $\triangle \mathrm{BCS}$, and $\triangle \mathrm{BW}$; few records, however, were available in the first $4 \mathrm{wk}$ of lactation, with the majority of records residing between wk 11 and 20 of lactation (Figure 1). The phenotypic correlation between measured and predicted values of $\mathrm{EI}, \mathrm{EB}, \triangle \mathrm{BCS}$, and $\triangle \mathrm{BW}$ ranged from 0.49 to $0.75,0.68$ to $0.73,0.63$ to 0.77 , and 0.68 to 0.73 , respectively, when the reduced data set comprising all component variables of $\mathrm{EB}$ (i.e., $\mathrm{n}=1,270$ ) was used to develop the equation (Table 1 ). When the full data set was used to predict $\triangle \mathrm{BCS}$ and $\triangle \mathrm{BW}(\mathrm{n}=23,848$ and 44,071, respectively), the correlation between measured and predicted values of $\triangle \mathrm{BCS}$ and $\triangle \mathrm{BW}$ ranged from 0.70 to 0.72 , and from 0.51 to 0.53 , respectively; the root mean square error (RMSE) of the respective equations ranged from 0.0018 to 0.0019 and from 0.29 to 0.30 .

Mean daily milk yield per cow was $19.5 \mathrm{~kg}$ with $4.4 \%$ fat and 3.6\% protein but varied across lactation (Table 2). Animals reached peak EB in late lactation (Table 2; Figure 3) even though peak EI occurred in mid lactation (Table 2, Figure 2). This was consistent for both measured and MIR-predicted EB and EI. Although associated standard deviations were large, trends in both measured and predicted $\triangle \mathrm{BCS}$ across lactation were similar in that animals tended to lose body condition in early lactation, lose minimal body condition in mid lactation, and put on body condition in late lactation (Table 2). This was corroborated by the trends of 
Table 1. Fit statistics ${ }^{1}$ of cross validation of prediction equations developed using the mid-infrared (MIR) spectrum (and milk yield) as predictor variables

\begin{tabular}{|c|c|c|c|c|c|c|c|c|}
\hline \multirow[b]{2}{*}{ Equation $^{2}$} & \multicolumn{2}{|c|}{ Energy intake } & \multicolumn{2}{|c|}{ Energy balance } & \multicolumn{2}{|c|}{ BCS change $^{3}$} & \multicolumn{2}{|c|}{ BW change ${ }^{4}$} \\
\hline & RMSE & $\mathrm{r}$ & RMSE & $\mathrm{r}$ & RMSE & $\mathrm{r}$ & RMSE & $\mathrm{r}$ \\
\hline PM & 24.03 & 0.66 & 21.56 & 0.69 & 0.0017 & 0.76 & 0.2580 & 0.69 \\
\hline PM + Milk & 21.11 & 0.75 & 21.08 & 0.73 & 0.0017 & 0.77 & 0.2631 & 0.70 \\
\hline $\mathrm{AM}+\mathrm{PM}$ & 27.98 & 0.49 & 21.53 & 0.71 & 0.0020 & 0.63 & 0.2598 & 0.68 \\
\hline $\mathrm{AM}+\mathrm{PM}+$ Milk & 23.81 & 0.67 & 22.63 & 0.68 & 0.0019 & 0.67 & 0.2516 & 0.73 \\
\hline
\end{tabular}

${ }^{1} \mathrm{RMSE}=$ root mean square error; $\mathrm{r}=$ correlation between measured and predicted values.

${ }^{2} \mathrm{PM}=\mathrm{MIR}$ spectrum of evening milk samples used for prediction; PM + Milk = MIR spectrum of evening milk samples and total test-day milk yield used for prediction; AM + PM = MIR spectrum of morning and evening milk samples used jointly for prediction; AM + PM + Milk = MIR spectrum of morning and evening milk samples and total test-day milk yield used for prediction.

${ }^{3} \mathrm{BCS}$ change $=$ daily change in BCS.

${ }^{4} \mathrm{BW}$ change $=$ daily change in $\mathrm{BW}$.

both measured and predicted $\triangle \mathrm{BCS}$ in Figure 4 . The standard deviation of measured and predicted $\triangle \mathrm{BW}$ across lactation was also large; however, trends across lactation were similar when measured and predicted $\Delta \mathrm{BW}$ were compared, with animals losing $\mathrm{BW}$ in early lactation but gaining $\mathrm{BW}$ in mid and late lactation (Table 2 and Figure 5).

\section{Genetic Parameters}

Genetic parameters of measured and predicted EI, EB, $\triangle \mathrm{BCS}$, and $\triangle \mathrm{BW}$ are given in Table 3 . The heritabilities of predicted EI and EB were lower than measured EI and EB. Although the repeatability of predicted EI was lower than that of measured EI, the repeatabilities of measured and predicted $\mathrm{EB}$ were similar (Table 3). Irrespective of whether based on a measured or predicted value, the heritability of the body-change traits (i.e., $\triangle \mathrm{BCS}$ and $\triangle \mathrm{BW}$ ) was less than the heritability of the other traits (i.e., EI and EB). The heritability of measured and predicted $\triangle \mathrm{BCS}$ was identical; however, the repeatability of predicted $\triangle \mathrm{BCS}(0.14)$ was less than that of measured $\triangle \mathrm{BCS}$ (0.43). When the full data set was used to calibrate the prediction equations of $\triangle \mathrm{BCS}$, the heritability of predicted $\triangle \mathrm{BCS}$ increased to 0.23 , whereas repeatability increased to 0.33 . As with $\triangle \mathrm{BCS}$, the heritabilities of both measured and predicted $\Delta \mathrm{BW}$ were similar, yet

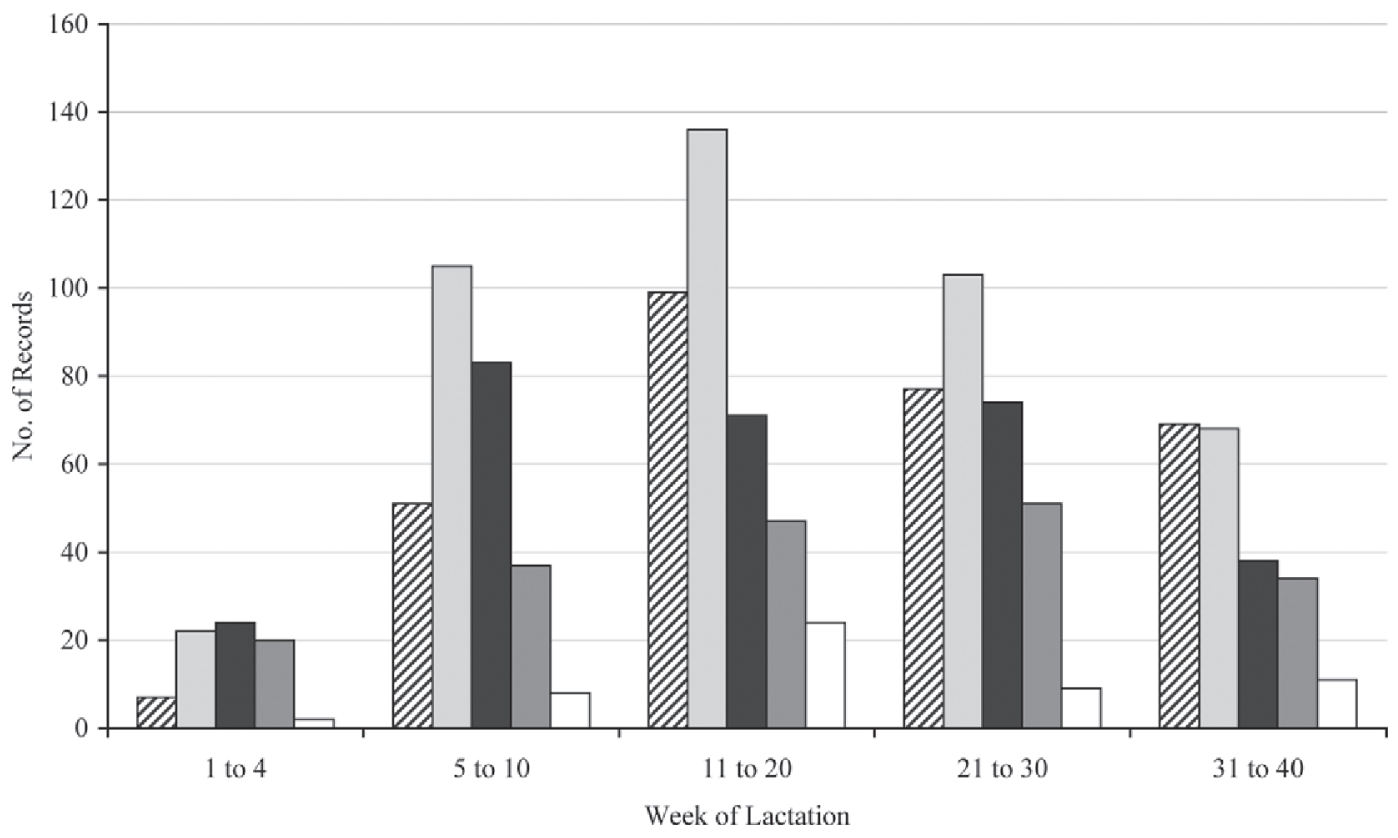

Figure 1. Number of records used to develop equations to predict energy intake, energy balance, daily BCS change, and daily BW change obtained within lactations 1 to $5(1=$ diagonal stripe; $2=$ light gray, $3=$ black, $4=$ dark gray, $5=$ white $)$ across weeks of lactation. 


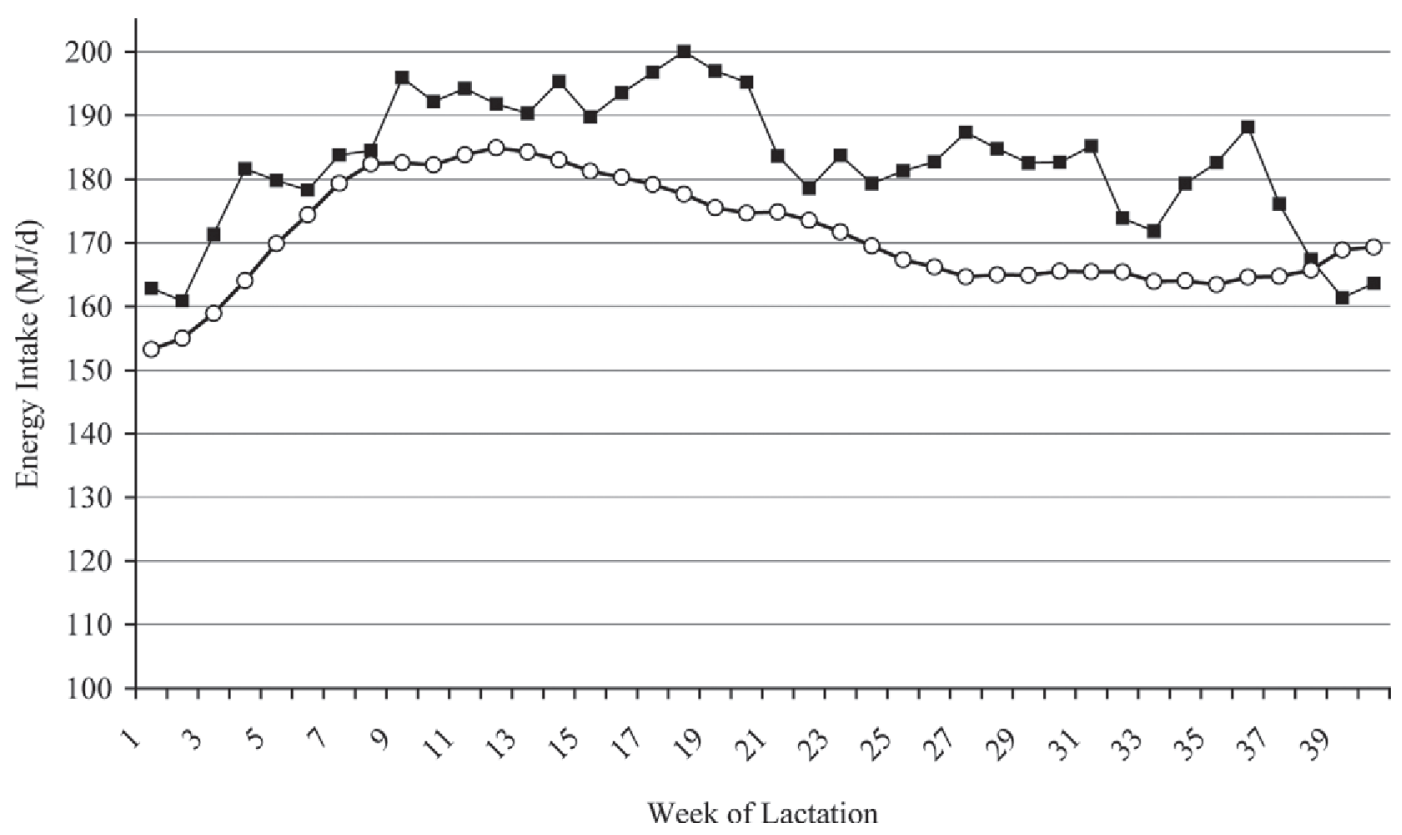

Figure 2. Measured ( $\square$ ) and mid-infrared-predicted $(\bigcirc)$ energy intake of animals in first to fifth parity across weeks of lactation.

the repeatability of predicted $\Delta \mathrm{BW}$ was poorer than that of measured $\Delta \mathrm{BW}$. However, when the full data set was used to calibrate equations to predict $\Delta \mathrm{BW}$, the repeatabilities of measured and predicted $\Delta \mathrm{BW}$ were similar and the heritability of predicted $\Delta \mathrm{BW}$ increased to 0.15 .

\section{Correlations}

Phenotypic correlations of both measured and predicted $\mathrm{EI}$ and $\mathrm{EB}$ with the component traits of $\mathrm{EB}$ (i.e., milk yield, milk composition, BCS, BW, $\triangle \mathrm{BCS}$, and $\triangle \mathrm{BW}$ ) are given in Table 4 ; the respective genetic correlations are in Table 5. The associations of both measured EI and predicted EI with all other traits were generally similar in strength and direction irrespective of whether phenotypic or genetic correlations were considered (Tables 4 and 5, respectively). Heavier animals that produced more milk had, on average, greater EI compared with smaller, lower-yielding animals. The genetic correlation between measured and predicted EI was 0.84 (Table 5).

Table 2. Number of records $(\mathrm{N})$ and means and standard deviations of component traits of energy balance and of measured and mid-infrared-predicted ${ }^{1}$ energy intake (EI), energy balance (EB), daily BCS change $(\Delta \mathrm{BCS})$, and daily $\mathrm{BW}$ change $(\triangle \mathrm{BW})$ included in the analyses across stage of lactation ${ }^{2}$

\begin{tabular}{|c|c|c|c|c|c|c|}
\hline \multirow[b]{2}{*}{ Item } & \multicolumn{2}{|c|}{ Early } & \multicolumn{2}{|r|}{ Mid } & \multicolumn{2}{|r|}{ Late } \\
\hline & $\mathrm{N}$ & Mean (SD) & $\mathrm{N}$ & Mean (SD) & $\mathrm{N}$ & Mean (SD) \\
\hline Milk (kg) & 19,086 & $24.5(6.1)$ & 48,939 & $20.8(5.5)$ & 33,789 & $14.7(4.7)$ \\
\hline Fat $(\mathrm{kg})$ & 17,799 & $4.5(0.8)$ & 46,277 & $4.2(0.8)$ & 30,578 & $4.8(0.9)$ \\
\hline Protein (kg) & 17,844 & $3.4(0.3)$ & 46,328 & $3.5(0.3)$ & 30,605 & $3.9(0.4)$ \\
\hline BCS (units) & 726 & $2.5(0.3)$ & 1,383 & $2.4(0.3)$ & 750 & $2.4(0.3)$ \\
\hline BW (kg) & 1,115 & $504(83)$ & 3,483 & $523(78)$ & 2,346 & $566(85)$ \\
\hline $\mathrm{EI}(\mathrm{MJ} / \mathrm{d})$ & 941 & $177.7(40.8)$ & 3,730 & $190.1(38.4)$ & 1,967 & $179.7(33.4)$ \\
\hline $\mathrm{EB}(\mathrm{MJ} / \mathrm{d})$ & 941 & $19.0(32.9)$ & 3,730 & $53.0(27.3)$ & 1,967 & $61.3(23.2)$ \\
\hline$\triangle \mathrm{BCS}\left(\right.$ units $\times 10^{-4}$ ) & 4,688 & $-46.9(24.0)$ & 11,129 & $-3.4(17.9)$ & 6,865 & $3.8(13.0)$ \\
\hline$\Delta \mathrm{BW}(\mathrm{kg})$ & 8,102 & $-0.13(0.45)$ & 21,166 & $0.23(0.26)$ & 15,489 & $0.29(0.26)$ \\
\hline \multicolumn{7}{|l|}{ Predicted } \\
\hline EI (MJ/d) & 16,814 & $169.4(38.5)$ & 42,245 & $178.8(33.3)$ & 31,627 & $166.7(26.7)$ \\
\hline $\mathrm{EB}(\mathrm{MJ} / \mathrm{d})$ & 16,574 & $11.4(35.0)$ & 41,281 & $38.4(26.3)$ & 31,507 & $45.5(24.2)$ \\
\hline$\Delta \mathrm{BCS}\left(\right.$ units $\left.\times 10^{-4}\right)$ & 18,082 & $-26.0(14.6)$ & 45,195 & $-6.1(12.3)$ & 30,971 & $3.4(13.8)$ \\
\hline$\Delta \mathrm{BW}(\mathrm{kg})$ & 17,833 & $-0.13(0.41)$ & 44,282 & $0.22(0.31)$ & 30,813 & $0.20(0.24)$ \\
\hline
\end{tabular}

${ }^{1}$ Fitting statistics of prediction equations used provided in Table 1.

${ }^{2}$ Early $=<60$ DIM; mid $=60$ to 180 DIM; late $=>180$ DIM. 


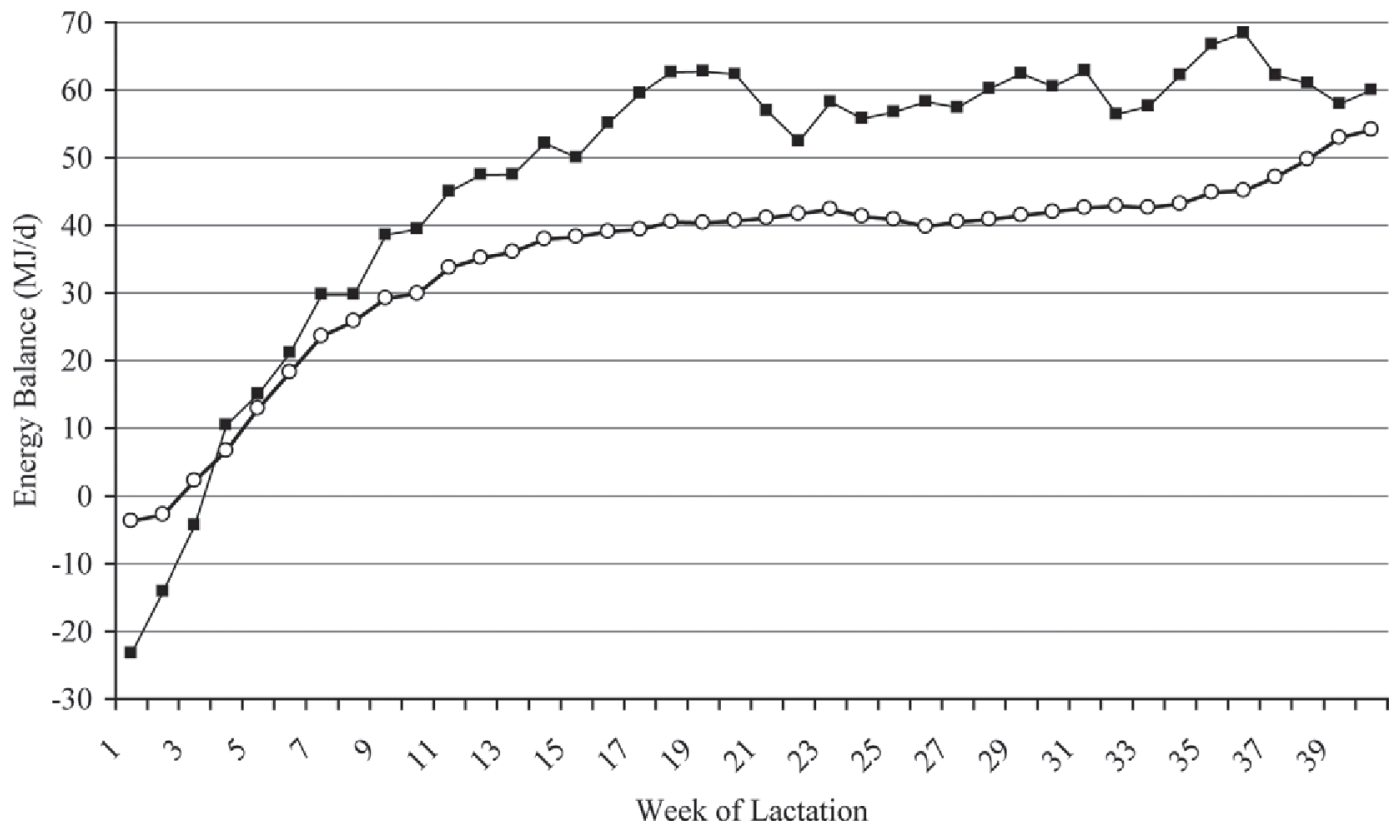

Figure 3. Measured ( $\mathbf{\square})$ and mid-infrared-predicted $(\bigcirc)$ energy balance of animals in first to fifth parity across weeks of lactation.

Phenotypic correlations among measured EB and its component traits sometimes differed in strength from the correlations between predicted EB and the component traits, although both sets of correlations tended in the same direction. The phenotypic correlations among measured and predicted EB with measured $\triangle \mathrm{BCS}$ and $\Delta \mathrm{BW}$ were similar $(\mathrm{r}=0.20$ to 0.28$)$; likewise, the correlations among measured and predicted EB with predicted $\triangle \mathrm{BCS}$ and $\triangle \mathrm{BW}$ were similar and ranged from 0.32 to 0.38 . Measured EB had a strong positive phenotypic correlation with measured EI $(\mathrm{r}=0.76)$. Although predicted EB was strongly correlated with predicted EI $(\mathrm{r}=0.68)$, the correlation between predicted EB and measured EI was weak $(r=0.12$; Table 4). The genetic correlations between measured EB and milk yield and composition differed in direction from

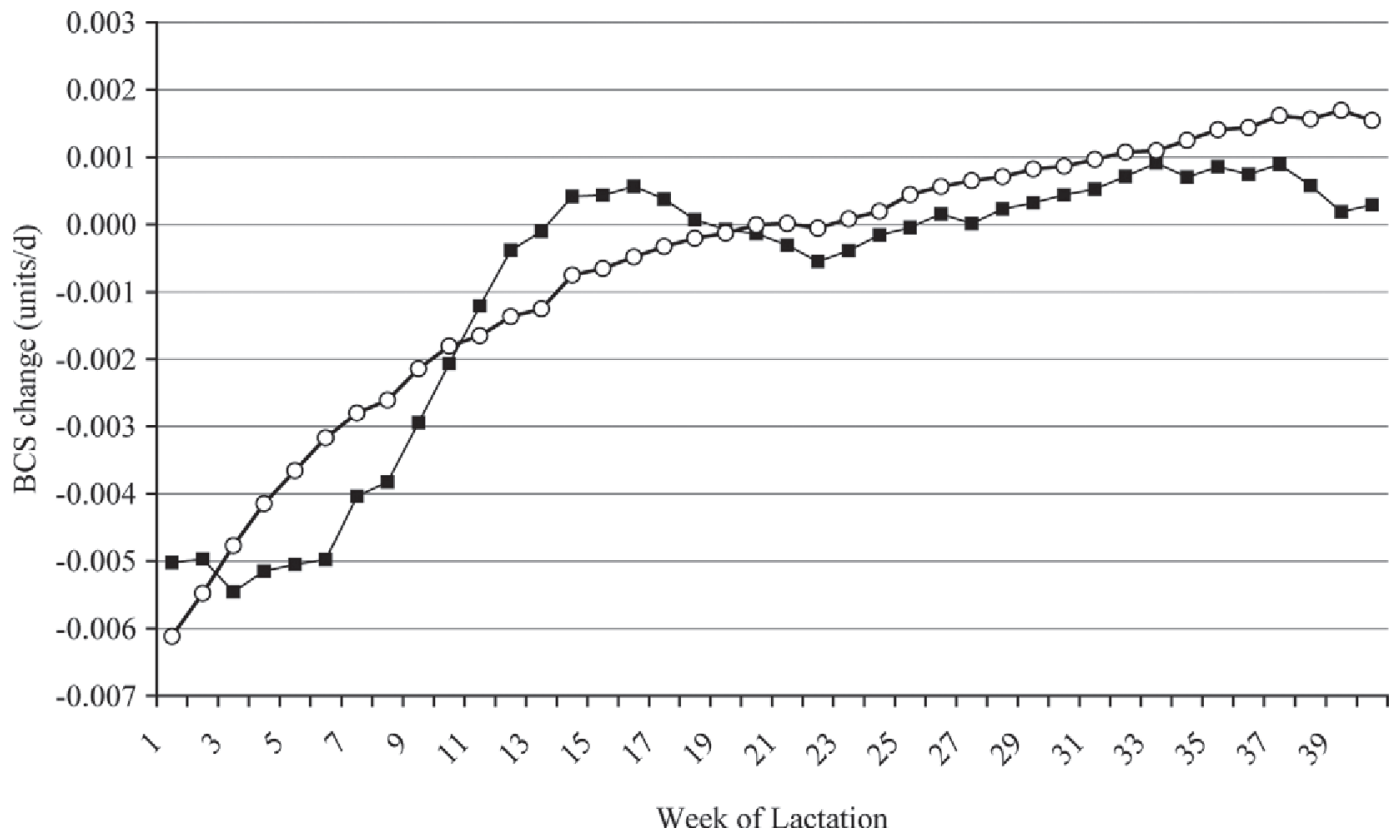

Figure 4. Measured ( $\square$ ) and mid-infrared-predicted $(\bigcirc)$ daily BCS change of animals in first to fifth parity across weeks of lactation. 
Table 3. Genetic standard deviation $\left(\sigma_{\mathrm{g}}\right)$, heritability $\left(\mathrm{h}^{2}\right.$; SE in parentheses), and repeatability (t; SE in

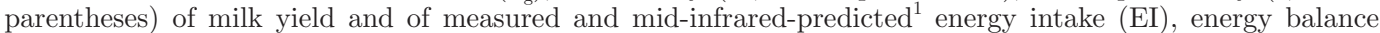
$(\mathrm{EB})$, daily BCS change $(\triangle \mathrm{BCS})$, and daily BW change $(\triangle \mathrm{BW})$

\begin{tabular}{lccccccc}
\hline & \multicolumn{3}{c}{ Measured } & & \multicolumn{3}{c}{ Predicted } \\
\cline { 2 - 4 } \cline { 7 - 8 } Trait & $\sigma_{\mathrm{g}}$ & $\mathrm{h}^{2}$ & $\mathrm{t}$ & & $\sigma_{\mathrm{g}}$ & $\mathrm{h}^{2}$ & $\mathrm{t}$ \\
\hline Milk (kg) & 2.37 & $0.37(0.01)$ & $0.55(0.01)$ & & - & - & - \\
EI (MJ/d) & 14.53 & $0.35(0.02)$ & $0.53(0.02)$ & & 11.18 & $0.20(0.01)$ & $0.33(0.01)$ \\
EB (MJ/d) & 8.12 & $0.16(0.02)$ & $0.28(0.02)$ & & 6.85 & $0.10(0.01)$ & $0.26(0.01)$ \\
$\Delta$ BCS (units) & 0.0004 & $0.07(0.02)$ & $0.43(0.01)$ & & 0.001 & $0.07(0.01)$ & $0.14(0.00)$ \\
$\Delta$ BW (kg) & 0.07 & $0.08(0.02)$ & $0.21(0.01)$ & & 0.07 & $0.06(0.00)$ & $0.10(0.00)$ \\
\hline
\end{tabular}

${ }^{1}$ Fitting statistics of prediction equations used provided in Table 1.

the respective correlations with predicted EB; however, the correlations were weak. Genetic correlations among measured and predicted EB with measured and predicted $\triangle \mathrm{BCS}$ and $\triangle \mathrm{BW}$ ranged from 0.16 to 0.49 . The genetic correlation between measured and predicted $\mathrm{EB}$ was 0.54 .

\section{Validation of Genetic Evaluations}

Predicted EI stratum was associated $(P<0.05)$ with measured EI. Least squares means for measured EI of the 668 feed intake test-day records ranked as low, medium, or high estimated breeding values for MIRpredicted EI were 154.3 $(\mathrm{SE}=2.15), 156.0(\mathrm{SE}=2.02)$, and $163.3(\mathrm{SE}=2.98) \mathrm{MJ}$, respectively. The regression coefficient of measured EI on MIR-predicted EI (as a linear covariate) was $0.82(\mathrm{SE}=0.25 ; P=0.001)$; higher-order polynomials did not improve the fit to the data, signifying that the relationship was linear.

\section{DISCUSSION}

For a trait to be considered in a breeding goal, it must (1) be important, (2) exhibit genetic variation, and (3) be amenable to routine recording on individual animals so as to achieve large numbers of unbiased records to aid high accuracy of selection; if phenotypes of the goal trait are not directly available, then the goal trait must be genetically correlated with a measurable heritable trait. Although the incorporation of genomic information into genetic evaluations somewhat reduces the necessity for routine access to phenotypic information, large quantities of phenotypic information are still required to generate the necessary phenotype-genotype associations for genomic predictions (Daetwyler et al., 2008). The economic importance of feed intake as a component of a breeding strategy to improve efficiency has been well established (Berry and Crowley, 2013). Additionally, ample genetic variation in feed intake has been documented

Table 4. Phenotypic correlations (SE in parentheses) between energy intake (EI) and energy balance (EB) calculated from phenotypic data (Measured) and predicted from the mid-infrared spectra (Predicted) and component variables of $\mathrm{EB}$

\begin{tabular}{|c|c|c|c|c|}
\hline \multirow[b]{2}{*}{ Item } & \multicolumn{2}{|c|}{ Energy intake } & \multicolumn{2}{|c|}{ Energy balance } \\
\hline & Measured & Predicted & Measured & Predicted \\
\hline Milk & $0.54(0.01)$ & $0.44(0.01)$ & $-0.05(0.02)$ & $-0.16(0.01)$ \\
\hline Fat & $-0.09(0.02)$ & $-0.01(0.01)$ & $-0.27(0.02)$ & $-0.04(0.01)$ \\
\hline Protein & $0.11(0.02)$ & $0.11(0.01)$ & $0.09(0.02)$ & $0.10(0.01)$ \\
\hline BCS & $0.12(0.05)$ & $0.09(0.02)$ & $0.03(0.05)$ & $-0.05(0.02)$ \\
\hline BW & $0.56(0.03)$ & $0.24(0.02)$ & $0.15(0.04)$ & $0.01(0.02)$ \\
\hline Measured $\triangle \mathrm{BCS}^{1}$ & $0.11(0.02)$ & $0.09(0.01)$ & $0.21(0.02)$ & $0.24(0.01)$ \\
\hline Measured $\Delta \mathrm{BW}^{2}$ & $0.18(0.02)$ & $0.08(0.01)$ & $0.28(0.01)$ & $0.20(0.01)$ \\
\hline Measured EB & $0.76(0.01)$ & $0.13(0.03)$ & - & $0.40(0.02)$ \\
\hline Measured EI & - & $0.57(0.02)$ & $0.76(0.01)$ & $0.12(0.03)$ \\
\hline Predicted $\triangle \mathrm{BCS}$ & $0.10(0.03)$ & $0.21(0.01)$ & $0.32(0.02)$ & $0.38(0.01)$ \\
\hline Predicted $\Delta \mathrm{BW}$ & $0.14(0.03)$ & $0.17(0.01)$ & $0.33(0.02)$ & $0.36(0.01)$ \\
\hline Predicted EB & $0.12(0.03)$ & $0.68(0.00)$ & $0.40(0.02)$ & - \\
\hline Predicted EI & $0.57(0.02)$ & - & $0.13(0.03)$ & $0.68(0.00)$ \\
\hline
\end{tabular}

${ }^{1} \triangle \mathrm{BCS}=$ daily change in BCS.

${ }^{2} \Delta \mathrm{BW}=$ daily change in $\mathrm{BW}$. 


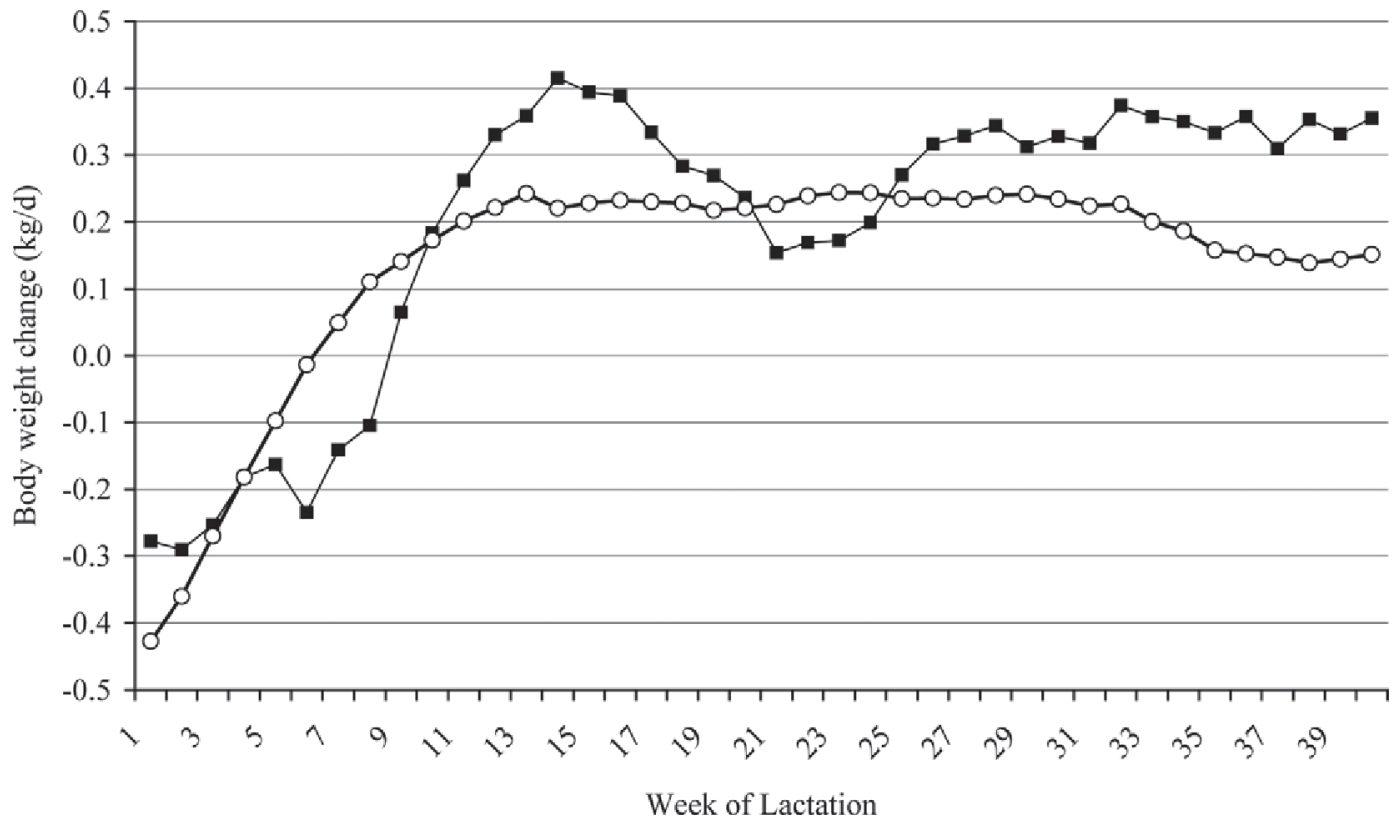

Figure 5. Measured ( $\mathbf{\square})$ and mid-infrared-predicted $(\bigcirc)$ daily BW change of animals in first to fifth parity across weeks of lactation.

in several populations (Berry and Crowley, 2013; Berry et al., 2014b); genetic variation in feed intake independent of differences in milk production and other energy sinks also clearly exists (Berry and Crowley, 2013). Despite this, feed intake is not explicitly included in any national dairy cow breeding index; live weight is often included as a proxy for maintenance requirement. The omission of feed intake from dairy cow breeding goals is simply an artifact of limited routine access to phenotypic data for feed intake. Energy balance is also of economic importance (Wall et al.,
2008 ) and genetic variation in EB is known to exist (Veerkamp et al., 2000; Berry et al., 2007), justifying its inclusion in breeding goals if information is available to differentiate between genetically divergent individuals. Moreover, EB in early lactation is known to be genetically correlated with animal health (Collard et al., 2000) and fertility (Veerkamp et al., 2000) and therefore also has merit in inclusion in multi-trait genetic evaluations as a predictor of these traits; this is especially true where phenotypic data for all goal traits (e.g., all livestock diseases) does not exist.

Table 5. Genetic correlations (SE in parentheses) between energy intake (EI) and energy balance (EB) as calculated from phenotypic data (Measured) and predicted from the mid-infrared spectra (Predicted) and component variables of $\mathrm{EB}$

\begin{tabular}{|c|c|c|c|c|}
\hline \multirow[b]{2}{*}{ Item } & \multicolumn{2}{|c|}{ Energy intake } & \multicolumn{2}{|c|}{ Energy balance } \\
\hline & Measured & Predicted & Measured & Predicted \\
\hline Milk & $0.69(0.03)$ & $0.50(0.03)$ & $0.26(0.07)$ & $-0.29(0.04)$ \\
\hline Fat & $-0.07(0.05)$ & $0.08(0.03)$ & $-0.15(0.06)$ & $0.17(0.04)$ \\
\hline Protein & $0.03(0.05)$ & $0.05(0.03)$ & $-0.01(0.06)$ & $0.16(0.04)$ \\
\hline BCS & $0.09(0.09)$ & $0.12(0.06)$ & $0.13(0.11)$ & $0.04(0.08)$ \\
\hline BW & $0.66(0.04)$ & $0.40(0.04)$ & $0.18(0.08)$ & $-0.01(0.05)$ \\
\hline Measured $\triangle \mathrm{BCS}^{1}$ & $0.15(0.14)$ & $0.22(0.12)$ & $0.38(0.15)$ & $0.37(0.12)$ \\
\hline Measured $\Delta \mathrm{BW}^{2}$ & $0.16(0.09)$ & $0.00(0.08)$ & $0.38(0.10)$ & $0.18(0.09)$ \\
\hline Measured EB & $0.73(0.04)$ & $0.35(0.09)$ & - & $0.54(0.09)$ \\
\hline Measured EI & - & $0.84(0.03)$ & $0.73(0.04)$ & $-0.05(0.10)$ \\
\hline Predicted $\triangle \mathrm{BCS}$ & $-0.02(0.07)$ & $0.15(0.04)$ & $0.16(0.08)$ & $0.45(0.04)$ \\
\hline Predicted $\Delta \mathrm{BW}$ & $0.00(0.07)$ & $-0.01(0.04)$ & $0.21(0.08)$ & $0.49(0.05)$ \\
\hline Predicted EB & $-0.05(0.10)$ & $0.47(0.04)$ & $0.54(0.09)$ & - \\
\hline Predicted EI & $0.84(0.03)$ & - & $0.35(0.09)$ & $0.47(0.04)$ \\
\hline
\end{tabular}

${ }^{1} \triangle \mathrm{BCS}=$ daily change in $\mathrm{BCS}$

${ }^{2} \Delta \mathrm{BW}=$ daily change in $\mathrm{BW}$. 
The objective of the present study therefore was to attempt to overcome the sole element precluding the inclusion of EI and EB in breeding goals - large quantities of (ideally low-cost) routinely available information to differentiate between genetically divergent animals for either trait. Despite the known moderate heritability for feed intake (Veerkamp and Thompson, 1999; Berry et al., 2007, 2014b) and EB (Veerkamp et al., 2000; Berry et al., 2007) in lactating dairy cows, sufficient data are still unlikely to be routinely generated on a genetically diverse population to generate accurate estimated breeding values for inclusion in selection decisions. Any measurement of EI or EB, therefore, must be amenable to routine measurement without affecting animal performance but should also be available at a low marginal cost. McParland et al. (2011, 2012, 2014) demonstrated the ability of patterns in the milk MIR spectrum of individual cows to phenotypically predict both EI and EB. The reported accuracy of prediction by McParland et al. (2012) is consistent with the accuracy of phenotypic prediction observed in the present study (Table 1) using a data set overlapping with that used by McParland et al. (2012). As previously reported (McParland et al., 2011, 2012), very high accuracy of prediction was not expected for traits investigated in this study because of diurnal variations in EI and $\mathrm{EB}$, the combination of measurement error of traits incorporated in $\mathrm{EB}$, and the subjective nature of BCS (McParland et al., 2011). Soyeurt et al. (2011) reported high accuracy of prediction of individual and groups of milk fats. However, the milk quality traits investigated by Soyeurt et al. (2011) had the advantage of an accurate gold standard method (i.e., gas chromatography) combined with both gold standard data and the MIR spectrum originating from a single milk sample. In contrast, the animal traits investigated in the present study are indirectly associated with the milk sample and, furthermore, they represent average values across a week (i.e., EI and therefore $\mathrm{EB}$ ) or changes over time (i.e., $\triangle \mathrm{BCS}$ and $\triangle \mathrm{BW}$ ). Dehareng et al. (2012) showed that the accuracy of predicting methane using MIR spectra varied according to the interval between milk sampling and methane quantification using the $\mathrm{SF}_{6}$ tracer method.

The moderate to strong phenotypic correlations between measured and predicted traits materialized in similar lactation profiles for both measured and predicted EI (Figure 2), EB (Figure 3), $\triangle \mathrm{BCS}$ (Figure 4), and $\triangle \mathrm{BW}$ (Figure 5). The MIR-predicted curves of EI and EB (Figures 2 and 3, respectively) deviated slightly from expectation in the first few and last few weeks of lactation, likely due to a paucity of records of measured traits in those weeks. Nonetheless, the lactation profiles for $\mathrm{EB}$ in the sample populations used in the present study were consistent with profiles described elsewhere (Berry et al., 2006; Friggens et al., 2007) with cows being in negative EB in early lactation. The observed extent and duration of negative EB in the present study was, however, not as great for MIR-predicted EB as for actual EB; similarly, the height of the EB lactation profile was less for MIR-predicted than for true EB. Although the predictive ability of actual mean EB is important for monitoring phenotypic performance, genetic evaluations, which rely on contemporary comparison, are robust to inaccuracies of the mean of the contemporary group (e.g., herd); the phenotypic standard deviation for predicted EB was very similar to that for measured EB.

The lactation profile for EI observed in the present study was similar to those documented in other dairy cow populations (Veerkamp and Thompson, 1999; Berry et al., 2007), increasing in early lactation. Irish dairy production systems rely heavily on grazed grass as the main constituent of the dairy cow diet. Cows therefore calve within a tight calving season coinciding with the initiation of grass growth. Because of this, mean herd lactation profiles closely follow the calendar year, and the depression in mid-season grass quality (Ganche et al., 2013; O'Neill et al., 2013) was reflected in a depression in EI in mid lactation in the present study. Intake capacity of dairy cows decreases as pregnancy progresses (Faverdin et al., 2011) and, because grazed grass is generally supplemented with concentrates or ensiled forages toward the latter half of the year (and therefore lactation), a plateau in EI in later lactation was expected and observed (Figure 2).

\section{Variance Components}

Although both the heritability and repeatability of predicted EI (0.20 and 0.33 , respectively; Table 3$)$ were less than those of measured EI ( 0.35 and 0.53 , respectively), both estimates were within the range of estimates reported from international dairy cow populations for heritability (0.08 to 0.61; Veerkamp et al., 2000; Berry et al., 2007, 2014b) and repeatability (0.46 to 0.84 ; Berry et al., 2014b). The lower heritability of predicted EI is almost exclusively due to a reduced genetic variance relative to measured EI. Nonetheless, the coefficient of genetic variation for EI was between 0.06 (predicted EI) and 0.08 (measured EI), signifying considerable exploitable additive genetic variation; mean expected difference in genetic merit for EI between the top and bottom decile of animals was almost $40 \mathrm{MJ} / \mathrm{d}$ using the parameters for MIR-predicted EI in the present study.

The sign of the phenotypic correlations between EI and performance was the same regardless of whether 
measured or predicted EI was considered, and all correlations were in-line with biological expectations: (1) heavier, higher-yielding cows of greater BCS ate more, and (2) greater EI was associated with greater EB. The signs of the genetic correlations, in general, were consistent with the corresponding phenotypic correlations or were close to zero. The genetic correlations between milk yield and EI suggest that milk yield explains 25 to $48 \%$ of the genetic variance in EI.

A 1-unit difference in estimated breeding value for $\mathrm{EI}$ is expected to materialize into a 1-unit difference in phenotypic performance for EI; the regression coefficient of $0.82(\mathrm{SE}=0.25)$ calculated in the present study was therefore not different from expectation. This, coupled with the observed difference in phenotypic EI in animals stratified on estimated breeding value for EI, suggests that genetic evaluations for MIRpredicted EI materialize in phenotypic differences in measured EI. Therefore, MIR-predicted EI could be useful in national breeding goals for selection on EI.

The genetic correlations between performance traits and predicted EB (Table 5) are, in general, more in line with expectations than the genetic correlations between performance traits and measured EB. The number of records included in the genetic analysis of predicted EB was 14 times the number of records available for the genetic analysis of measured EB, and this difference was reflected in larger associated standard errors of the genetic correlations in the latter. Selection for increased milk yield is expected to result in, on average, lower $\mathrm{EB}$, as evidenced by the negative genetic correlation $(-0.29)$ between milk yield and predicted EB; this correlation is almost identical to the genetic correlation of -0.27 reported by Veerkamp et al. (2000) in Dutch Holstein-Friesian cows. Energy intake is expected to be positively genetically correlated with EB; Veerkamp et al. (2000) documented a genetic correlation of 0.62 between DMI and EB in Holstein dairy cows. Although MIR-predicted EI was positively genetically correlated with both predicted and measured EB $(\mathrm{r}=0.47$ and 0.35, respectively), measured EI was not correlated $(-0.05)$ with MIR-predicted EB although it was associated with a large standard error (Table 5). The phenotypic correlation between MIR-predicted EB and MIR-predicted EI was 0.68; however, it was 0.12 between MIR-predicted EB and measured EI. This may be due to the structure of the data; the majority of measured traits were recorded before the collection of MIR information from milk samples since 2008. The phenotypic correlation between MIR-predicted EI and MIR-predicted EB when only animals with measured EI were included in the analysis was $0.43(\mathrm{SE}=0.03)$.

The low heritability of $\triangle \mathrm{BCS}$ and $\triangle \mathrm{BW}$ in the present study corroborates previously documented heritability of these traits (Pryce et al., 2001; Berry et al., 2002). Body condition score change is a known indicator of $\mathrm{EB}$; cows in negative $\mathrm{EB}$ will lose body condition to generate energy for support of bodily functions. This association was also supported by the correlation of 0.16 to 0.45 between $\triangle \mathrm{BCS}$ and $\mathrm{EB}$ in the present study, which is similar to the phenotypic correlations of 0.31 to 0.52 documented by Veerkamp et al. (2000) between $\mathrm{EB}$ and $\triangle \mathrm{BW}$ in early-lactation Dutch primiparous cows; Veerkamp et al. (2000) did not consider $\triangle \mathrm{BCS}$ in their analysis. Therefore, the similarity in heritabilities of $\mathrm{EB}(0.10$ to 0.16$)$ and $\triangle \mathrm{BCS}(0.07)$ is not unexpected, and the former is consistent with the range in heritability (0.06 to 0.33 ) for EB reported previously (Veerkamp et al., 2000; Berry et al., 2007). However, because genetic merit for $\triangle B C S$ and EB can be predicted with reasonable accuracy using milk MIR, phenotypic information for these traits, and thus estimates of genetic merit, can be routinely generated at negligible marginal cost on a large population of milk recorded cows and thus high accuracy of selection is achievable despite the lower heritability. Of course, the accuracy of selection for measured EB can never be greater than the genetic correlation between MIR-predicted and measured EB (i.e., 0.54). It is the genetic variation in a trait, therefore, that is arguably of greatest importance for genetic gain when ample phenotypic information exists for use in genetic evaluations. The coefficient of genetic variation for EB across lactation was between 0.16 (measured EB) and 0.19 (MIR-predicted EB). Using the statistics for predicted $\mathrm{EB}$, the mean difference in genetic merit for $\mathrm{EB}$ between the top $10 \%$ and bottom $10 \%$ of animals is expected to be $24 \mathrm{MJ} / \mathrm{d}$.

\section{CONCLUSIONS}

The MIR spectrum is a useful predictor of EI, EB, $\triangle \mathrm{BCS}$, and $\triangle \mathrm{BW}$. Heritability of all MIR-predicted traits was similar to their respective measured traits, and exploitable genetic variation existed for all MIRpredicted traits. Both EI and EB were moderately to strongly genetically correlated with measured EI and $\mathrm{EB}$, respectively. Moreover, estimated breeding values for EI materialized as phenotypic differences in EI, suggesting that the inclusion of such MIR-predicted traits would result in genetic gain for the measured traits.

\section{ACKNOWLEDGMENTS}

The authors gratefully acknowledge funding from the Irish Department of Agriculture, Food and Marine (Dublin, Ireland), Research Stimulus Fund project 13/ S4/96, RAPIDFEED, from the Marie Curie project In- 
ternational Research Staff Exchange Scheme SEQSEL, and from the RobustMilk project, financially supported by the European Commission under the Seventh Framework Programme, Grant Agreement KBBE-211708.

\section{REFERENCES}

AFRC (Agricultural and Food Research Council). 1993. Energy and Protein Requirements of Animals. An advisory manual prepared by the AFRC Technical Committee on Responses to Nutrients. CAB International, Wallingford, UK.

Banos, G., and M. P. Coffey. 2010. Genetic association between body energy measured throughout lactation and fertility in dairy cattle. Animal 4:189-199.

Beam, S. W., and W. R. Butler. 1999. Effects of energy balance on follicular development and first ovulation in postpartum dairy cows. J. Reprod. Fertil. Suppl. 54:411-424.

Berry, D. P., M. L. Bermingham, M. Good, and S. J. More. 2011. Genetics of animal health and disease in cattle. Ir. Vet. J. 64:5.

Berry, D. P., F. Buckley, R. D. Evans, P. G. Dillon, M. Rath, and R. F. Veerkamp. 2002. Genetic parameters for level and change of body condition score and body weight in dairy cows. J. Dairy Sci. 85:2030-2039.

Berry, D. P., M. P. Coffey, J. E. Pryce, Y. de Haas, P. Lovendahl, N. Krattenmacher, J. J. Crowley, Z. Wang, D. Spurlock, K. Weigel, K. Macdonald, and R. F. Veerkamp. 2014b. International genetic evaluations for feed intake in dairy cattle through the collation of data from multiple sources. J. Dairy Sci. 97:3894-3905.

Berry, D. P., and J. J. Crowley. 2013. Genetics of feed efficiency in dairy and beef cattle. J. Anim. Sci. 91:1594-1613.

Berry, D. P., B. Horan, M. O'Donovan, F. Buckley, E. Kennedy, M McEvoy, and P. Dillon. 2007. Genetics of grass dry matter intake, energy balance, and digestibility in grazing Irish dairy cows. J. Dairy Sci. 90:4835-4845.

Berry, D. P., J. F. Kearney, K. Twomey, and R. D. Evans. 2013. Genetics of reproductive performance in seasonal calving dairy cattle production systems. Ir. J. Agric. Food Res. 52:1-16.

Berry, D. P., R. F. Veerkamp, and P. G. Dillon. 2006. Phenotypic profiles for body weight, body condition score, energy intake, and energy balance across different parities and concentrate feeding levels. Livest. Sci. 104:1-12.

Berry, D. P., E. Wall, and J. E. Pryce. 2014a. Genetics and genomics of reproductive performance in dairy and beef cattle. Animal 8:105-121.

Coffey, M. P., G. C. Emmans, and S. Brotherstone. 2001. Genetic evaluation of dairy bulls for energy balance traits using random regression. Anim. Sci. 73:29-40.

Collard, B. L., J. C. M. Dekkers, D. Petitclerc, and L. R. Schaeffer. 2000. Relationships between energy balance and health traits of dairy cattle in early lactation. J. Dairy Sci. 83:2683-2690.

Daetwyler, H., B. Villanueva, and J. A. Woolliams. 2008. Accuracy of predicting the genetic risk of disease using a genome-wide approach. PLoS ONE 3:e3395.

De Marchi, M., V. Toffanin, M. Cassandro, and M. Penasa. 2014. Invited review: Mid-infrared spectroscopy as a phenotyping tool for milk traits. J. Dairy Sci. 97:1171-1186.

Dehareng, F., C. Delfosse, E. Froidmont, H. Soyeurt, C. Martin, N. Gengler, A. Vanlierde, and P. Dardenne. 2012. Potential use of milk mid-infrared spectra to predict individual methane emission of dairy cows. Animal 6:1694-1701.

Dillon, P. G., and G. Stakelum. 1989. Herbage and dosed alkanes as a grass management technique for dairy cows. Ir. J. Agric. Res. 8:104. (Abstr.)

Edmonson, A. J., I. J. Lean, L. D. Weaver, T. Farver, and G. Webster. 1989. A body condition scoring chart for Holstein dairy cows. J. Dairy Sci. 72:68-78

Faverdin, P., C. Baratte, R. Delagarde, and J. L. Peyraud. 2011. GrazeIn: a model of herbage intake and milk production for graz- ing dairy cows. 1. Prediction of intake capacity, voluntary intake and milk production during lactation. Grass Forage Sci. 66:29-44.

Friggens, N. C., P. Berg, P. Theilgaard, I. R. Korsgaard, K. L. Ingvartsen, P. Løvendahl, and J. Jensen. 2007. Breed and parity effects on energy balance profiles through lactation: Evidence of genetically driven body energy change. J. Dairy Sci. 90:5291-5305.

Ganche, E., L. Delaby, M. O'Donovan, T. M. Boland, and E. Kennedy. 2013. Direct and carryover effect of post-grazing sward height on total lactation dairy cow performance. Animal 7:1390-1400.

Gilmour, A. R., B. J. Gogel, B. R. Cullis, and R. Thompson. 2009 ASReml User Guide Release 3.0 VSN International Ltd., Hemel Hempstead, UK.

Kennedy, E., M. O'Donovan, L. Delaby, and F. P. O'Mara. 2008. Effect of herbage allowance and concentrate supplementation on dry matter intake, milk production and energy balance of early lactating dairy cows. Livest. Sci. 117:275-286.

McCarthy, J., B. McCarthy, B. Horan, K. M. Pierce, N. Galvin, A. Brennan, and L. Delaby. 2014. Effect of stocking rate and calving date on dry matter intake, milk production, body weight, and body condition score in spring calving, grass-fed dairy cows. J. Dairy Sci. 97:1693-1706.

McParland, S., G. Banos, B. McCarthy, E. Lewis, M. P. Coffey, B O'Neill, M. O'Donovan, E. Wall, and D. P. Berry. 2012. Validation of mid-infrared spectrometry in milk for predicting body energy status in Holstein-Friesian cows. J. Dairy Sci. 95:7225-7235.

McParland, S., G. Banos, E. Wall, M. P. Coffey, H. Soyeurt, R. F. Veerkamp, and D. P. Berry. 2011. The use of mid-infrared spectrometry to predict body energy status of Holstein cows. J. Dairy Sci. 94:3651-3661.

McParland, S., E. Lewis, E. Kennedy, S. G. Moore, B. McCarthy, S. T. Butler, and D. P. Berry. 2014. Mid-infrared spectrometry of milk as a predictor of energy intake and efficiency in lactating dairy cows. J. Dairy Sci. 97:5863-5871.

Moore, S. G., T. Fair, P. Lonergan, and S. T. Butler. 2014. Genetic merit for fertility traits in Holstein cows: IV. Transition period, uterine health, and resumption of cyclicity. J. Dairy Sci. 97:27402752

O'Mara, F. 1997. A Net Energy System for Cattle and Sheep. Department of Animal Science and Production, Faculty of Agriculture, University College Dublin, Ireland.

O'Neill, B. F., M. H. Deighton, B. M. O'Loughlin, F. J. Mulligan, T. M. Boland, M. O'Donovan, and E. Lewis. 2011. Effects of a perennial ryegrass diet or total mixed ration diet offered to springcalving Holstein-Friesian dairy cows on methane emissions, dry matter intake, and milk production. J. Dairy Sci. 94:1941-1951.

O'Neill, B. F., E. Lewis, M. O'Donovan, L. Shalloo, F. J. Mulligan, T. M. Boland, and R. Delagarde. 2013. Evaluation of the GrazeIn model of grass dry-matter intake and milk production prediction for dairy cows in temperate grass-based production systems: 1 . Sward characteristics and grazing management factors. Grass Forage Sci. 68:504-523.

Pryce, J. E., M. P. Coffey, and G. Simm. 2001. The relationship between body condition score and reproductive performance. J. Dairy Sci. 84:1508-1515.

SAS Institute. 2009. SAS User's Guide: Statistics. SAS Inst. Inc., Cary, NC.

Soyeurt, H., F. Dehareng, N. Gengler, S. McParland, E. Wall, D. P. Berry, M. Coffey, and P. Dardenne. 2011. Mid-infrared prediction of bovine milk fatty acids across multiple breeds, production systems, and countries. J. Dairy Sci. 94:1657-1667.

Veerkamp, R. F., J. K. Oldenbroek, H. J. Van der Gaast, and J. H. J. Van der Werf. 2000. Genetic correlation between days until start of luteal activity and milk yield, energy balance, and live weights. J. Dairy Sci. 83:577-583.

Veerkamp, R. F., and R. Thompson. 1999. A covariance function for feed intake, live weight, and milk yield estimated using a random regression model. J. Dairy Sci. 82:1565-1573.

Wall, E., M. P. Coffey, and P. R. Amer. 2008. A theoretical framework for deriving direct economic values for body tissue mobilization traits in dairy cattle. J. Dairy Sci. 91:343-353. 